\title{
Markers for domestic violence in women.
}

\author{
R L Spedding, M McWilliams, B P McNicholl, C H Dearden
}

Accident and

Emergency

Department, Royal

Victoria Hospital,

Grosvenor Road,

Belfast

R L Spedding

B P McNicholl

C H Dearden

Department of Social and Community

Science, University of

Ulster, Belfast

M McWilliams

Correspondence to: Dr R L Spedding,

Consultant in Accident and Emergency, Warrington

Hospital, Warrington, Lovely

Lane, Cheshire WA5 1 QG.

Accepted 29 May 1999

\begin{abstract}
Objective-To determine injury patterns and characteristics specific to domestic violence in women who present to the accident and emergency (A\&E) department.

Design-A retrospective case note review of all female assaults over a one year period. The subjects were women who disclosed that their injuries were due to assaults by either a current or a previous male partner. Controls were female assault victims not injured by domestic violence.
\end{abstract}

Setting-A medium sized urban A\&E department.

Results-There were 500 female assaults out of 48169 new attendances. Domestic violence was disclosed in 103 cases. The following features were significantly associated with domestic violence in women: multiple injuries ( $p<0.001)$ (especially to the head and arms), fractures $(p<0.05)$, loss of consciousness $(p<0.05)$, abdominal injuries $(p<0.05)$, pregnancy $(p=0.01)$, injury occurring on "stairs" $(p=0.01)$, and general practitioner referral $(\mathbf{p}<0.01)$. Conclusions-Women who have been assaulted are more likely to have been injured during domestic violence if they sustain multiple injuries (including fractures), abdominal injuries, have lost consciousness, or have been referred by their general practitioner. These markers may help medical staff to identify more cases of undisclosed domestic violence. The markers need to be tested further in a prospective study.

( Accid Emerg Med 1999;16:400-402)

Keywords: domestic violence; markers; women; assault

In this study, domestic violence is defined as "the abuse of a women by a current or former male partner". ${ }^{2}$ A lifetime prevalence of $25 \%$, in the UK, highlights domestic violence as a public health issue. ${ }^{1}$ Between $5 \%$ and $11 \%$ of women who present acutely to the accident and emergency (A\&E) department attend as a result of domestic violence. ${ }^{3-5}$ Many publications describe the epidemiology of domestic violence in patients attending an $A \& E$ department. ${ }^{1-11}$ In comparison, few studies have attempted to identify patterns of injury and presentation that help distinguish between domestic violence and non-domestic violence. ${ }^{12-15}$ There is a lack of case-control studies. ${ }^{14}$ This is the first UK study with a control group.

Identification of markers would be important in alerting clinicians to the possibility of domestic violence, as it is known that many cases are not disclosed, ${ }^{459}$ and that attacks tend to be repeated with both increasing frequency and severity. ${ }^{8} 9^{15-17}$

The study examines female assaults, comparing assaults due to domestic violence with a control group of women who were not injured by domestic violence.

\section{Methods}

One year of the A\&E department medical and nursing case notes were hand searched by one author (RLS) to identify all female assaults. These were classified into two groups: disclosed domestic violence defined as "an assault by a current or previous male partner" and a control group (assault by a non-family member). All assaults by other relatives/family members were excluded. Other groups were excluded if the assailant had not been documented or was unknown. Patient and control groups were compared for injury and referral patterns. There were no directives to doctors during the study year to look for a history of domestic violence.

The A\&E department is in an urban setting and does not see patients under the age of 13 .

Statistical analysis was performed with Epi-Info using a $\chi^{2}$ test.

\section{Results}

In the year studied there were 48169 new patient attendances: 21121 were women and of these 7723 were due to trauma. There were 500 assaults on females of which 103 were due to disclosed domestic violence. There were 140 patients in the control group (table 1). The control group contained those assaults where the assailant had been documented as a stranger, mugger, robber, next door neighbour,

Table 1 Assaults on women during one year

Domestic violence

Control violen

Assaults by other family members $\quad 46$

Others

Total

500 
Table 2 Number and anatomical distribution of soft tissue injuries

\begin{tabular}{lcc}
\hline Site & $\begin{array}{l}\text { Disclosed domestic } \\
\text { violence }(n=103)\end{array}$ & Controls $(n=140)$ \\
\hline Head/face & 130 & 74 \\
Neck & 22 & 18 \\
Trunk & 49 & 17 \\
Legs & 18 & 11 \\
Arms & 71 & 36 \\
Total & 290 & 156 \\
\hline
\end{tabular}

Table 3 Number of fractures

\begin{tabular}{llll}
\hline Disclosed domestic violence & $(19 / 103)$ & Control (8/140) & \\
\hline Nose & 4 & Skull & 1 \\
Jaw/cheek & 2 & Nose & 1 \\
Shoulder & 2 & Jaw/cheek & 2 \\
Ribs & 4 & Forearm & 1 \\
Forearm & 2 & Finger & 2 \\
Hand & 5 & Ankle & 1 \\
\hline
\end{tabular}

law enforcement officer, or sporting opponent. The "others" group were assaults where the assailants were other relatives (sister, aunt) or a combination of relatives and all cases where the assailant had not been documented. The median ages of the two groups was similar: women with disclosed domestic violence 34 (17-72) years and the control group 35 (14-85) years.

Assaults due to disclosed domestic violence had a median of three injuries per person compared with a median of one in the control group $(p<0.001)$. There were more injuries to the head and arms in the domestic violence group ( $p<0.001$; table 2 ). There were 19 fractures in the disclosed domestic violence group and only eight in the control group $(p<0.05$; table 3 ). There was only one patient in the control group who had lost consciousness compared with nine in the domestic assaults group $(p<0.05)$. Of these nine, seven presented more than 13 hours after they had lost consciousness $(p=0.002)$.

Seven of the group with disclosed domestic violence were pregnant. There was only one pregnancy in the control group $(p=0.01)$. There were no abdominal injuries in the control group, but in the group disclosing domestic violence nine women had abdominal injuries $(p=0.004)$. Three of these women were pregnant.

None of the control group was referred by their general practitioner unlike 12 of the domestic violence group $(p<0.01)$. A history of domestic violence was noted in two of these general practitioner referral letters.

None of the control group had fallen on the stairs but there were five women in the domestic violence group who initially stated that their injuries were due to a fall downstairs (Fisher's exact test, $p=0.01$ ). While still in the $A \& E$ department, they later volunteered that domestic violence had been the cause of their injuries.

\section{Discussion}

This case-control study shows that there are significant differences in the patterns of injury in the women who disclose domestic violence compared with a control group of female assault victims. Unlike non-accidental injury in chil- dren, the markers for undisclosed domestic violence have not been fully determined. It is likely that some of the features of disclosed domestic violence may also be present in patients with undisclosed domestic violence. We are unable to study retrospectively the undisclosed victims of domestic violence because by their very nature they are silent. Similarly, a prospective study will not pick up all these hidden patients because many women (up to $36 \%)^{3}$ do not disclose domestic violence through fear of humiliation, embarrassment, or retribution. ${ }^{12} \mathrm{Up}$ to $11 \%$ of women will deny the cause of their injuries even when directly questioned. ${ }^{3}$ By default, disclosed injury patterns are the best markers currently available for hidden domestic violence. Alerted doctors can then question patients directly, resulting in disclosures from those women who are hoping for focused questions. ${ }^{12} 71819$ A more thorough search for other undisclosed injuries can then be made.

This study did not include other presentations of domestic violence, those women who did not volunteer a history of physical assault, or those who feigned another cause for their injuries. No attempt was made to quantify the psychological injury associated with assault.

It is well known that doctors do not record a descriptive history of an assault. ${ }^{1-3}{ }^{17}$ In this retrospective study, many cases (211) (table 2) were excluded because of lack of information about the assailant or the assailant's relationship to the victim.

Although these results are only from one hospital and may not be representative of the greater population, they are similar to those of a recent study. ${ }^{14}$ This study from New Zealand showed that injuries to the head and fractures were more common in disclosed domestic violence. However, only the most serious injury for each patient was analysed and therefore they did not find that multiple injuries were significant.

Further prospective research is needed. Until this is done, we would recommend that the markers identified in this study should be used to alert doctors to the question of domestic violence. These are:

(1) Delay in presentation.

(2) Referral by a general practitioner.

(3) Pregnancy. ${ }^{416}$

(4) History of loss of consciousness. ${ }^{13}$

(5) Multiple injuries.

(6) Abdominal injuries. ${ }^{16}$

(7) Injuries to the arms and face. ${ }^{1316} 19$

(8) Fractures. ${ }^{13}$

These criteria apply only to women who say they have been assaulted but may not initially admit domestic violence. Both this study and future studies of patterns of injury in domestic violence are confounded by the fact that it is impossible to ensure that a matching control group does not contain women with undisclosed domestic violence

\section{Conclusion}

The study has identified injury patterns, in women, which are significantly associated with disclosed domestic violence. Any woman who presents with the markers identified in this study 
should alert A\&E department doctors to the possibility of undisclosed domestic violence.

We would like to thank Mr D Bennett for help with statistic and Lynda and Frank at the University of Ulster.

Conflict of interest: none.

Funding: none.

1 Bewley S, Friend J, Mezey G. Violence against women. London: RCOG Press, Royal College of Obstetricians and Gynaecologists, 1997.

$2 \mathrm{McW}$ illiams M, McKiernan J. Bringing it out in the open. London: HMSO, 1993.

3 Hayden SR, Barton ED, Hayden M. Domestic violence in the emergency department: how do women prefer to disclose and discuss the issues? $f$ Emerg Med 1997;15:44751.

4 Abbot J, Johnson R, Koziol-McLain J, et al. Domestic violence against women: incidence and prevalence in an violence against women: incidence and prevalence in an accident and emer

5 Goldberg WG, Tomlanovich MC. Domestic violence victims in the emergency department: new findings. $\mathscr{f} A M A$ 1984;251:3259-64.

6 Isaac NE, Cinches RL. Emergency department response to battered women in Massachusetts. Ann Emerg Med 1994;23:855-8.

7 McLeer S, Anwar R. A study of battered women presenting in an emergency department. Am $\mathcal{F}$ Public Health 1989;79: 65-6.

8 McLeer SV, Anwar R. The role of the emergency physician in the prevention of domestic violence. Ann Emerg Med 1987;16:1151-61.
9 Roberts GL, O'Toole BI, Lawrence JM, et al. Domestic violence victims in a hospital emergency department. Med $\mathfrak{J}$ Aust 1993;159:307-10.

10 Fothergill NJ, Hashemi K. A prospective study of assault victims attending a suburban accident and emergency department. Arch Emerg Med 1990;7:772-7.

11 Stark E, Flitcraft A, Frazier W. Medicine and patriarchal violence; the social construction of a private event. Int $\mathcal{F}$ Health Serv 1979;9:461-93.

12 Appleton W. The battered women syndrome. Ann Emerg Med 1980;9:84-91.

13 Muelleman RL, Lenaghan PA, Pakieser RA. Battered women: injury locations and types. Ann Emerg Med 1996;28:486-92.

14 Farnslow JL, Norton RN, Spinola CG. Indicators of assault-related injuries among women presenting to the emergency department. Ann Emerg Med 1998;32:341-8.

15 Stark E, Flitcraft A, Frazier W. Wife abuse in the medical setting: an introduction for health personnel. Washington DC: setting: an introduction for health person

$16 \mathrm{McF}$ arlane J, Parker B, Soeken K, et al. Assessing for abuse during pregnancy; severity and frequency of injuries and associated entry into prenatal care. $\mathcal{F} A M A$ 1992;267:3176-

17 Makower RM, Pennycook AG, Crawford R. Women attending an accident and emergency department after an assault. f Accid Emerg Med 1995;12:15-19.

18 Friedman LS, Samet JH, Roberts MS, et al. About victimisation experiences: a survey of patient preferences and phy sician practices. Arch Intern Med 1992;152:1186-90.

19 Rounsville B, Weissman MM. Battered women. Int $\mathcal{f}$ Psychiatry Med 1978;88:191-202.

\section{Intercollegiate Academic Board of Sport and Exercise Medicine}

The Intercollegiate Academic Board of Sport and Exercise Medicine has been established to function in a role equivalent to a specialist advisory committee on behalf of, and reporting to, its parent colleges and faculties who are full members of the Academy of Medical Royal Colleges. In addition, the board has a category of associate membership for appropriate bodies who are not full members of the academy.

The board plans to develop a higher specialty training programme in sport and exercise medicine which will meet the standards of the Specialist Training Authority and result in successful trainees being awarded a Certificate of Completion of Specialist Training. The board will develop the curriculum, syllabus, regulations, appraisal, and assessment procedures that will act as the basis for a four year Higher Specialty Training Programme in Sport and Exercise Medicine. This will take time but it is planned to have the basis of the programme established by July 2000 .

The Intercollegiate Academic Board of Sport and Exercise Medicine believes that the development of this subspecialty interest will help improve the fitness of the nation, the management of soft tissue injuries, and the care offered to individuals participating in exercise for the benefit of their health as well as competitive athletes. The board recognises that these ambitions can only be achieved with the support of a wide range of educational and administrative bodies committed to sport and exercise medicine and hopes to liaise closely with them while developing its plans for the future.

The Intercollegiate Academic Board of Sport and Exercise Medicine can be contacted by writing to its administrative base at the Royal College Of Surgeons of Edinburgh, Nicolson Street, Edinburgh EH8 9DW. 